\section{Society and mind}

\section{Clive Gamble}

The Last Neanderthal: The Rise, Success, and Mysterious Extinction of Our Closest Human Relatives. By Ian Tattersall. Macmillan Publishing USA: 1995. Pp. 208. \$39.95.

The Neanderthal Legacy: An Archaeological Perspective from Western Europe. By Paul Mellars. Princeton University Press: 1996. Pp. 471. \$69.50, £49.50.

WHAT makes the Neanderthals different? For the physical anthropologist, intent on cladistic trainspotting, it is four small hidden features of their skulls rather than the obvious massive brow ridges, low domed crania and powerful, short-legged frames. What often matters to the archaeologist, faced with an abundant legacy of stone tools, are similar small details about how they made these artefacts, rather than the wider aspect of Neanderthal culture, which lacked art, architecture and ritual.

Any account of these 'deep-time' people must reconcile the unglamorous labours of exacting scientific enquiry with the broader enquiry that makes the Neanderthals, and in particular their fate, so fascinating. The minutiae of the specialist must be translated into a context where the stones and bones can determine the contribution of Neanderthals to later evolution. Were Neanderthals replaced by modern-looking people entering their territory in Europe and the Middle East, or is there a seamless continuity between them and the present diverse peoples in this region? Do we look and act like Neanderthals every day of our lives or do we encounter them only in museums?

The title of Ian Tattersall's book leaves us in no doubt about his conclusion. In a richly illustrated and wide-ranging survey, he concludes that we can use Neanderthals as a mirror to ponder our own position in evolutionary history. Such reflection is assisted not only by the excellent colour plates, which present the skulls as art objects, but also by a succinct account of how evolution works and can be applied to the five million years of the hominid fossil record. Tattersall concludes that Neanderthals were different from modernlooking humans in both anatomy and behaviour, but not inferior. Rare for a scientist, he even gives us two short biographies of the last Neanderthal. One, a male, is hunted down by the tall "odd-looking strangers" - a vignette reminiscent of $\mathrm{H}$. $\mathrm{G}$. Wells's extermination of the loathsome Grisly Folk. The other, more in the style of Jorge Luis Borges's parable "The Witness", has a female contemplating her life in the society of the strangers with their clever talk. Tattersall concludes that we will never know in such precise detail what hap-

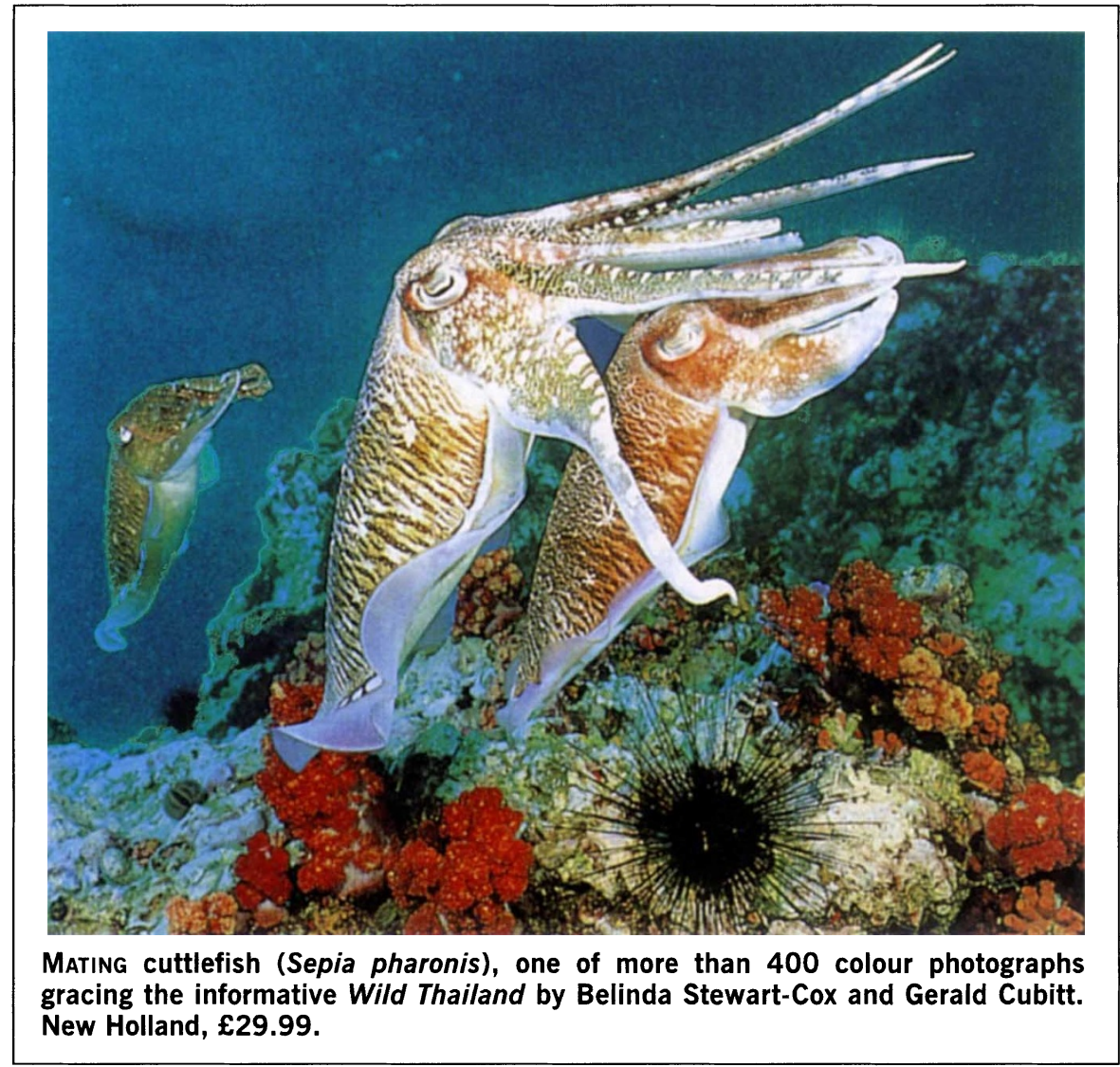

pened but he nonetheless favours the first of these scenarios. What is clear from his book, which extends across that part of the Old World inhabited by the Neanderthals, is the long period of coexistence between the two populations: the last Neanderthal fossils in Zafarraya cave in southern Spain date from some 27,000 years ago - at least 13,000 years after modern-looking humans first appeared in Europe. This is one piece of evidence that allows the author to regard the notion that Neanderthals gave rise to modern humans as totally discredited. Many of its main supporters do not even appear in his index.

Such a firm view is not shared by Paul Mellars. His title refers to the archaeological record rather than to any surviving Neanderthal genes. Instead of covering the Neanderthal world, he concentrates on their heartland in southwest France. His in-depth treatment of the archaeology is led by his study of Neanderthal stone tools, set in the context of how Neanderthals obtained subsistence and raw materials from the region and how they organized their camp sites beneath the limestone cliffs of the Dordogne. $\mathrm{He}$ demonstrates that two aspects of the behaviour of Neanderthals make them more similar to us. First, he concludes that variation in their distinctive stone tools corresponds to cultural patterning, where separate long-term traditions of making and doing were fostered by social distance. Second, he argues that during the 200,000 years Neanderthals were around, their behaviour changed.

Because culture and adaptive change are the archaeological hallmarks of modern humans, Mellars sensibly asks us to re-think the capabilities of Neanderthals and re-assess their difference from the moderns. But when faced with the overwhelming evidence for cultural change in the Upper Palaeolithic revolution, Mellars falls back less convincingly on the idea that complex language made the difference and so led to Neanderthal replacement. Conviction is lacking because, although he devotes chapters to the neglected areas of Neanderthal mind and society, there is less indication of how such themes can be tested with the stone-tool and camp-site evidence. He points archaeologists in typically clear fashion towards the need to overhaul the notion of society and mind as applied to Palaeolithic data. These notions are today locked in their own Neanderthal era and, until we free ourselves, the rich rewards from interdisciplinary research, to which archaeology with its massive databases of past action could contribute, will remain unrealized. A first step would be to harness the discussion of how evolution works from Tattersall's book and apply its principles to the richly detailed Neanderthal legacy where theories of change take second place to the catalogue of difference and similarity.

Clive Gamble is in the Department of Archaeology, University of Southampton, Southampton SO17 1BJ, UK. 